THURSDAY, FEBRUARY 23, I888.

\section{PHYSICAL SCIENCE AND THE WOOLWICH EXAMINATIONS.}

SINCE the appearance of our article of January 26 considerable interest has been manifested in this question, and during the past week important communications on the subject have come from the Secretary of State for War, and from the head master of Clifton College. We learn from Mr. Wilson's letter to the Times that the new regulations are not only calculated to do harm by the discouragement of science, but that they are also retrograde in another very important particular. By increasing the range of the obligatory examination in mathematics, though they will not very greatly affect the selection of candidates, yet, in the case of very many of them, by compelling wider and less thorough study, they will damage the training in that subject.

In answer to a question put by Mr. Howorth, in the House of Commons on February 15 , the Secretary of State for War is reported to have said that the new regulations are intended to encourage those subjects which it is believed can be least easily crammed; to give a preponderance to those subjects which are to the majority of officers of greatest practical importance ; and that the new regulations are to be of permanent application.

Are the regulations calculated to achieve these purposes? We think it can be shown very clearly that they are not. It is therefore with renewed hope that discussion will lead to their amendment that we enter upon the following examination of them.

(I) The new regulations are intended to encourage subjects which it is believed can be least easily crammed. Mr. Wilson, as we have already pointed out, has indicated that in the case of mathematics they will distinctly tend to encourage quantity at the expense of quality. With regard to science subjects, the examination statistics which we published in 1884 clearly proved that experimental science was not then chosen by candidates on account of susceptibility to cram, for it was at that time less frequently selected than any other subject by successful candidates. During the three or four years that preceded $\mathrm{x} 884$, a branch of experimental science was offered by only 22 per cent. of the successful candidates; since that date the numbers have risen, notwithstanding the increased thoroughness of some parts of the examination; and in 1887 about 38 per cent. of the successful candidates offered a branch of experimental science. This development is noteworthy, and may be considered to indicate an increased appreciation of the value of such work by teachers and students, since it has taken place in spite of the subject being rather a bad than a good one from the mark-winning point of view, and also during a period notable for improvement in some parts of the examination. Geography and geology, which may be, as some hold, more susceptible of cramming than chemistry and physics, show no corresponding tendency. In 1887 this subject was taken up by a distinctly smaller proportion of successful candidates than in the years that preceded 1884 .

There does not appear, then, to be any justification for treating science as a subject more easy to cram than VOL XXXVII. -No. 956. others that are more favourably treated. Had it beei true that it is so, it would have been selected by a greater proportion of candidates formerly, and it would certainly have been discouraged by the nature of the examination during the last few years.

(2) Are the subjects selected those most calculated to be of practical importance to a majority of officers in the Fngineers and Artillery? A flood of light is thrown upon this point by the course of instruction given to the cadets in the Royal Military Academy.

During the first year of training at Woolwich, cadets will study in the compulsory courses the following subjects:-

Mathematics,

Field Fortification,

Military Topography,

French or German,

Chemistry and Physics,

Model Drawing,

for which 3000 marks are given.

$\begin{array}{lrrr}, & 2000 & , & , \\ , & 2000 & , & , \\ , & 1000 & , & , \\ , & 1000 & , & , \\ \text {," } & 300 & , & ,\end{array}$

During the second year of training, the cadets are divided into two classes. Those who are selected for the Engineers will then study, in addition to purely professional subjects-

$\begin{array}{lll}\text { Mathematics, for which } & 2000 \text { marks are given. } \\ \text { Chemistry and Physics, ,, } & \text { 1000 ,", ", } \\ \text { Freehand Drawing, } & \text { 1000 ,", ," }\end{array}$

In the case of the Artillery cadets during their second year, chemistry and physics alone of the ten or eleven subjects examined in the entrance competition are considered to be of sufficient practical importance to be retained.

Thus it stands admitted by the military authorities, according to their own regulations for the education of cadets, that, of the subjects examined in the competition for Woolwich, experimental science stands next to mathematics as a subject of practical importance in the training of officers for the scientific branches of the army.

That very great weight should be given to mathematics and modern languages in the examinations for Woolwich cadetships is obviously proper; but since it is admitted, by the courses of instruction in the Royal Military Academy, that capacity for and extensive training in experimental science form part of the necessary equipment of an officer of Engineers or Artillery, a system of selection which includes no means whatever of securing youths capable of such studies in the preliminary examination, and which places youths of scientific power at such considerable disadvantages in the competitive part of the examination, plainly needs to be amended, in the interest both of the service and of the candidates. We do not doubt that those who get into the Academy will be excellently. taught there, but under these regulations many will be rejected who are eminently fitted to do well, in favour of others who are less gifted with the qualities that are admittedly most valuable.

The Committee who framed these regulations has, we fear, forgotten that the Professors at Woolwich will not create a capacity for science work by the mere teaching of science to the successful cadets, and that the utmost they can do in the case of those whose talents are linguistic rather than scientific, ${ }^{1}$ will be to compel them to acquire by hard, uncongenial labour the necessary minimum of knowledge that is required in the subsequent examinations. It is abundantly r The enormous value to be given to mojern languages is likely to result in many such winning admision to Woolwich in future. 
evident that the War Office Committee has made a serious mistake. The new regulations, so far as experimental science is concerned, are needless as precautions against cramming; they will not give due weight to the subjects which are, by their own showing, of most practical importance to officers ; and they will influence most unfairly the selection of candidates by giving no chance for scientific power to tell in the results of the examinations.

There is another side of this question which is of very great public importance, viz. the influence of these and other examinations on school work in general. Regulations such as those now in force at Sandhurst, and those about to come into operation at Woolwich, make it increasingly difficult for science subjects to maintain their proper place in schools where they are already adopted, and hinder their adoption elsewhere. Many of the ablest youths in our public schools enter as competitors in these and other examinations, and as they must offer the subjects that pay best, such regulations as those under discussion lower the general standard of school work by constantly withdrawing from the science classes a large proportion of the best students. At present good work in science pays less well very often than mediocrity in other subjects. This, as was pointed out by Sir Lyon Playfair in his Presidential Address to the British Association in I 885 , helps to arrest progress in science teaching. We do not, of course, claim that the interests of science in schools should be allowed to outweigh the manifest needs of the public services. But the fact that public examinations exercise a potent influence, not only on the education of the candidates, but also on the general tendency of school work, throws great responsibility on those who control them, and makes it our duty to urge that this influence shall not be lost sight of, especially when, as in the case of Woolwich cadets, an aptitude for experimental science is admittedly a quality that will be of great practical value in the professional work of the successful competitors.

\section{THE MOTHS OF INDIA.}

A Catalogue of the Moths of India. Compiled by E. C. Cotes, First Assistant to the Superintendent, Indian Museum, and Colonel C. Swinhoe, F.L.S., F.Z.S., \&c. Part I. Sphinges. Part II. Bombyces. (Calcutta: Printed by the Superintendent of Government Printing, 1887.)

$\mathrm{T}$ is not too much to say that the task of writing a catalogue of the moths of India is one which might appal an entomologist of far longer experience than either of the authors of this work. For when we consider that no general catalogue or revision of the Heterocera exists more recent than that of Guenée, that almost the whole of the types of the described species are in England, whilst both the authors of this book are in India, and that the number of Indian moths is so great that in the two first families alone upwards of 1600 species or supposed species are catalogued, it is evident that the difficulty of such a work is enormous ; and as the authors are not known as lepidopterists of long standing, and are resident on opposite sides of India, no one would expect too much from the first attempt at what has long been very much wanted-namely, some work which would enable the rapidly-growing circle of working naturalists in India to know what has already been described and where the descriptions have appeared.

I think, therefore, that the cordial thanks of all will be given to Colonel Swinhoe and Mr. Cotes for their bold attempt to fill this blank, and that no one will be too critical as to how their task has been done when the great difficulties under which they labour are remembered. There is not a word of introduction to say to what extent cither of the authors is responsible for the work, but I believe that Mr. Cotes is really the compiler, and that Colonel Swinhoe, whose collection is much richer than that of the Indian Museum in the species which occur in Western India, has added such additional species and notes as he possesses.

The plan of the work is nothing more than a bare catalogue of names and references, with localities so far as known to the compilers or to the authors of these names; and, as we see that in some genera almost all the species are unknown to either of the authors except from the descriptions or plates, it is evident that a large proportion of the names are names and nothing more.

In the genus Syntomis, for instance, we find forty-two supposed species catalogued, of which fifteen are described by Moore, nine by Walker, and ten by Butler; of all these only eleven are in Colonel Swinhoe's collection, and thirteen in that of the Indian Museum, and we da not find that a single attempt has been made to discover how many of these forty-two names represent distinct species.

As long as authors continue to do as Messrs. Moore, Butler, and the late Mr. Walker have so freely donenamely, to describe anything they do not personally know, with little regard to what has already been described-it is evident that, when their views as to variation are also extremely narrow, a great many synonyms must result, and we think a little genuine work would tend to show that of the forty-two supposed species of Syntomis not more than perhaps twenty really exist in nature. It is, however, quite as probable that while not more than twenty distinct species are described from India, at least twenty more remain undiscovered, for it is hardly possible for anyone who does not know India personally to understand how infinitesimal our knowledge of the moths is, except in some half-dozen localities like Bombay, Calcutta, and Sikkim; and even in such places as these what we know is but little compared to what we do not know. Surely here is a field for study and amusement which must attract many who will, sooner or later, provide the materials and collect the knowledge necessary for a "Catalogue raisonné," but the sooner a good example is set, by the careful ant scientific description of the genera and species which are known, with due regard to distribution and variation, the more and better will be the work done.

A book is projected by Mr. F. Moore, whose knowledge of Indian moths is certainly greater than that of all other entomologists combined; but it is sincerely to be hoped that he will not adopt such a plan or style of work as his recently published "Lepidoptera of Ceylon." The bulk and cost of such a work on the Lepidoptera of India would quite prevent its use by those most likely to use it to advantage, and even if it was completed in 